\title{
Lacunes: Small, deep cerebral infarcts
}

\author{
C. Miller Fisher, M.D.
}

LACUNES may be defined as ischemic infarcts of restricted size in the deeper parts of the brain. Absent from the cerebral and cerebellar cortex, they are best known in the chronic healed stage when they form irregular cavities, 0.5 to $15 \mathrm{~mm}$. in diameter, principally in the basal ganglia and basis pontis (Figs. 1, 2, 3, 4 , and 5). Although outnumbering all the other varieties of cerebrovascular lesion combined, ${ }^{1}$ lacunes are not as well known to the neurologist as they deserve to be. The present paper is a survey of the pathological findings in a series of patients with lacunes autopsied at a general hospital. While it was possible to correlate lacunes with the occurrence of cerebral atherosclerosis and arterial hypertension, the clinical details in the cases were so deficient that a good clinicopathologic correlation could not be made.

\section{HISTORY}

The term lacune can be traced back to Durand-Fardel ${ }^{2}$ who in his treatise on softening of the brain described the pathological findings in his case No. 78 as follows: "The striatum on each side showed a certain number of small lacunes with no associated alteration of color or consistency from whose surface there extended a fine meshwork containing very small vessels." Elsewhere in the same monograph the author described for the first time état criblé (riddled with shot or sievelike) consisting of numerous canals or small round holes in the cerebral tissue from each of which a small vessel projected and which were located in the striatum, thalamus, and cerebral white matter. That he was not referring to criblé lesions in case 78 when he wrote "lacunes" is fairly certain, since in the same specimen both lacunes and état criblé were described.

In the following years the efforts of the pathologist were mainly directed to settling the dispute as to whether brain softening was a form of encephalitis or, according to the doctrine of Virchow, a variety of ischemic necrosis due to arterial occlusion or failure of the circulation. ${ }^{3}$ It is hardly surprising, therefore, that many years passed before the term lacune came into common use. Proust, ${ }^{3}$ in his thesis, asked whether lacunes, the small pisiform cavities so frequent in the corpus striatum and with the appearance of small infarcts, were not due to changes in the capillaries. "These cavities which have received the name lacunes are usually no larger than a lentil or small pea." He had noted their irregular and, at times, jagged outline; their content of fibrous tissue and clear liquid; and their location in the striatum, thalamus, and, more rarely, the pons. The presence of severe atheroma of the cerebral arteries in such cases did not escape the author. He stated, probably erroneously, that Durand-Fardel was referring to état criblé when he used the term lacunes. Proust thought that lacunes were variously due to an infarct, a hemorrhage, or sometimes a "disorganization" and stated that a plaque jaune is the cicatrix of an infarct in gray matter, while a lacunar cyst is the cicatrix of an infarct in white matter.

Laborde $^{4}$ observed "pisiform lacunes" in the striatum and thalamus, recognizing them as a type of softening, albeit the true nature of softening was not known to him. He was astonished at the complete indifference to them on the part of Durand-Fardel. ${ }^{2}$

Bourneville 5 found 2 "lacunes," $10 \times 2 \mathrm{~mm}$. and $5 \times 2 \mathrm{~mm}$., in the corona radiata in a patient with hemianesthesia. Landouzy ${ }^{6}$ referred to a "hemorrhagic lacunar scar" in the centrum semiovale. Raymond ${ }^{7}$ described small cerebral lesions in elderly patients dying of uremia, but in his opinion the paralysis did not seem to be the result of such lacunes but to an

From the Department of Neurology, Massachusetts General Hospital, Boston

Dr. Fisher's address is Department of Neurology, Massachusetts General Hospital, Fruit Street, Boston, Massachusetts 02114 . 


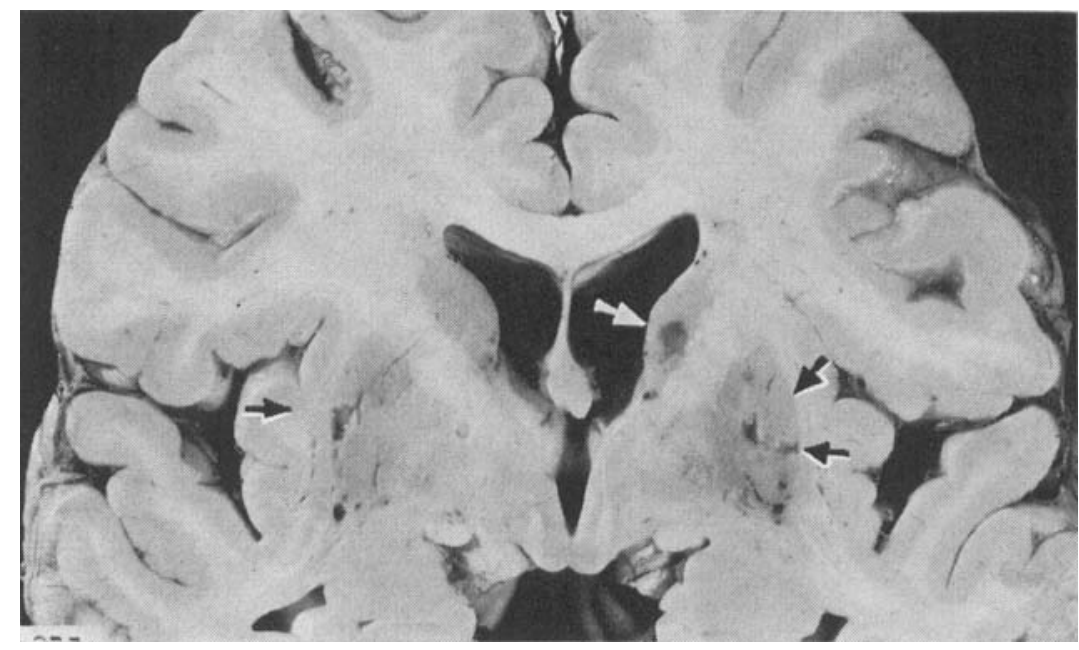

Fig. 1. Section showing lacunes in putamen and head of caudate nucleus

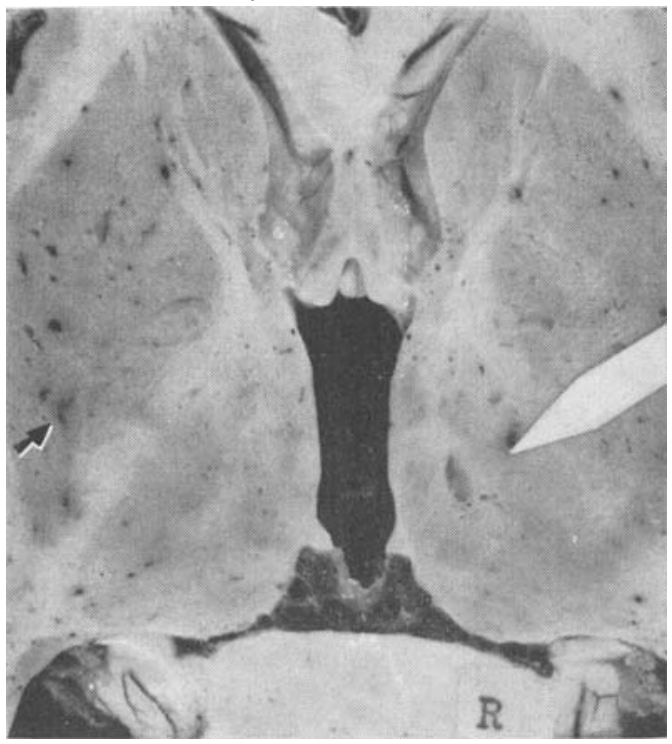

Fig. 2. Lacunes in thalamus and opposite putamen

accompanying cerebral edema. Comte ${ }^{8}$ in his monograph on pseudobulbar paralysis referred either directly by name to lacunes or to lesions that fit the description of lacunes in 9 of the 11 cases studied pathologically. The infarcts often corresponded clinically to a mild hemiplegia.

Marie $^{9}$ and Ferrand ${ }^{10}$ were the first, however, to clearly define the lesion anatomically and describe the main features of the corresponding clinical picture. Marie, in whose laboratory Ferrand worked, in 1901 presented a paper which was largely a detailed summary

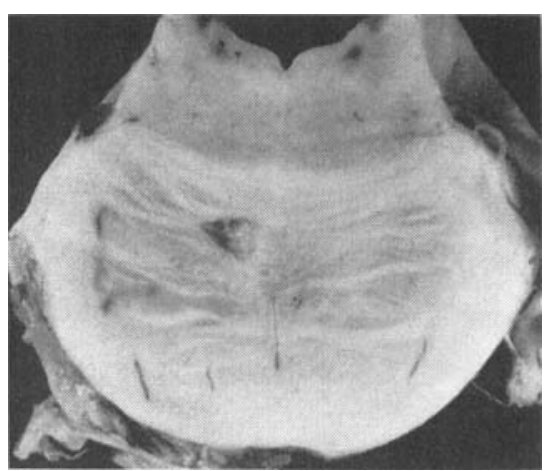

Fig. 3. Lacune in basis pontis

of Ferrand's monograph which was to appear in 1902. In an analysis of 50 patients with "foyers lacunaires de désintegration" examined postmortem in a hospital for chronically ill men, he found lacunes in the lenticular nucleus in 45 . Other sites of predilection included the pons (especially), thalamus, central white matter, internal capsule, centrum ovale, corpus callosum, and, rarely, cerebellum. None was found in the midbrain, medulla, or spinal cord. In 32, more than one lacune was found; in 13, more than 2 were found; and in 1 case, 10 were found. He recognized the typical lacunar cavity as a healed infarct resulting from "rupture or obliteration" of a perforating artery or its branches due to local arteriosclerosis. In the 50 brains studied, an intracerebral hemorrhage had also occurred sixteen times and superficial softening seven times. The author suggested that in these cases hemorrhage might be due 


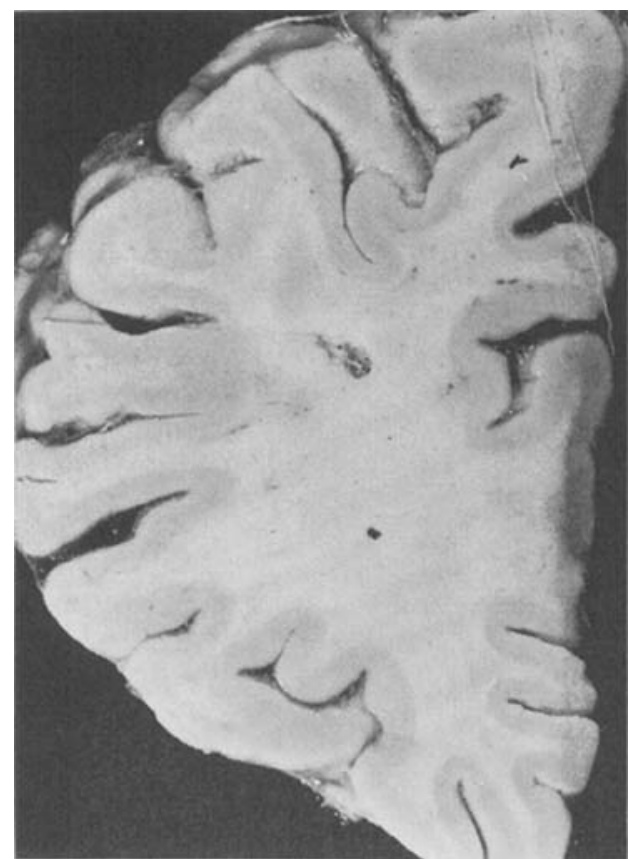

Fig. 4. Lacune in frontal white matter

to rupture of a vessel that had lost the support of its surrounding tissue through necrobiosis. A vascular occlusion was not found.

The clinical picture was of a sudden hemiplegia followed by good recovery. At times there was only a clumsiness of a limb. A second characteristic was the marche à petits pas of Dejerine. Hemianesthesia occurred in only 8 patients, and hemianopia was not recorded. No permanent deviation of the tongue or face and no contracture of the limbs occurred. Although dysarthria was common, permanent aphasia was not encountered; dysarthria was more conspicuous in patients with a left-sided hemiplegia. Pseudobulbar palsy was common, psychic functions were weakened, and intelligence was diminished. Finally, dementia with or without incontinence could ensue. Explosive laughing and crying were frequent. The average age of onset was 60 years, but the age in one instance was 28 and in another, 40. The average age at death was 68 .

Marie, in referring to " 50 cases of état lacunaire observed on my service," introduced the term état lacunaire which has since been used to designate the pathological state of multiple lacunes. The author appended a brief discourse on "état criblè" of Durand-Fardel which he described as holes seen on a horizontal section of the brain, especially in the white matter of the anterior portion of the island of Reil, in the temporal lobe, and also in the lenticulostriate area. These "criblures" he said were perivascular dilations without manifest alteration of the adjacent tissue. $\mathrm{He}$ also referred to "état vermoulu" (worm-eaten), his term for limited destruction of the cortical gray matter with the production of alveoli. It is thus plain that état lacunaire was an appropriate extension of the terminology used for the other 2 states, état criblé and état vermoulu. Marie also discussed cerebral porosity (état porose) which he correctly attributed to postmortem gas formation. Dupré and Devaux ${ }^{11}$ described one patient without clearly distinguishing lacunes from the holes of criblé.

Ferrand, ${ }^{10}$ in his essay on the hemiplegia of old age, reported his findings in 88 cases, presumably including the 50 reported by Marie. The lacunes, which were the size of a bean or pea or miliary size, were found in the same locations as described by Marie. The lenticular nucleus was involved in 64 cases ( 25 bilateral); thalamus, 35 ( 6 bilateral); internal capsule, 25 ( 1 bilateral); caudate nucleus, 18 ( 2 bilateral); pons, 24 ; centrum semiovale, 14 ; and corpus callosum, 3 . In 14, extensive bilateral lesions were found. Recurrence was evident by 217 lacunes in the 88 patients, an average of more than 2 lesions per person. The author observed that lesions involving the internal capsule arose primarily in gray masses and extended to the capsule. No lesions were found in the cortex, cerebral peduncles, or medulla.

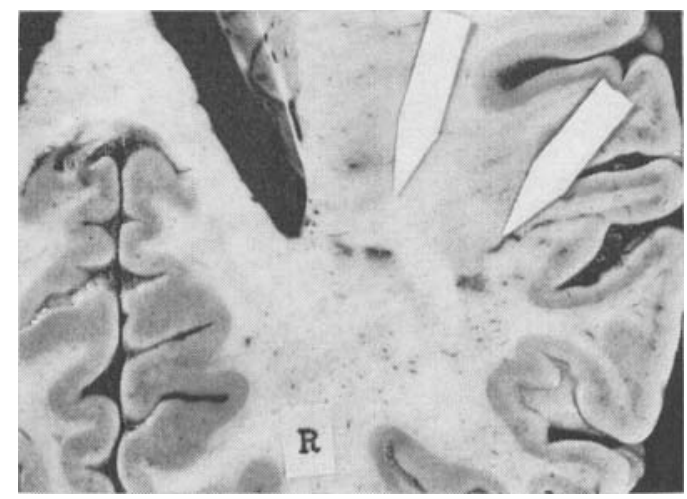

Fig. 5. Lacunes in deep parietal white matter 
Ferrand's description of the pathological changes in a lacune were most thorough. In each lacune he found a centrally placed vessel that was never occluded, although internal thickening with narrowing of the lumen was prominent. He thought that occlusion had possibly existed originally but disappeared by the time the patient died. Though no aneurysmal dilation of an artery was seen within the lacune, Ferrand, with Marie, believed these vessels might give way and cause a hemorrhage. Leukocytes and macrophages surrounded the vessel within the lesion, and in some cases there was a considerable amount of orange hematoidin. The pathogenesis of the lesions was apparently a sclerosis of small arteries producing a chronic encephalitis that healed by sclerosis, but the author considered the possibility that the lesion was a special entity, distinct from softening, hemorrhage, and encephalitis. He regretted that serial sections had not been undertaken while looking for occlusion of the artery of supply. The vessels at the base of the brain were always very atheromatous. For detection of lesions, a Flechsig horizontal cut just below the beak of the corpus callosum was recommended, this single section showing $99 \%$ of the lacunes. Often the liver was enlarged and the heart hypertrophied and dilated. The kidneys were frequently small.

Among the other abnormalities he found in the nervous system were several that no longer are considered related to lacunes, namely, adherence of the dura mater to the cranial vault, opalescence and thickening of the pia mater in the frontal region, convolutional atrophy, atrophy of the corpus callosum, unusual prominence of the arteries of the basal ganglia, ventricular dilation, ridging of the ventricular roof (like a puppy's palate), enlargement and cyst formation in the choroid plexus, and cloudiness of the pia over the posterior columns of the spinal cord.

Although most patients were over the age of 60 years, $16 \%$ were under 55 and $24 \%$ between 55 and 60 at the time of the first lacunar ictus. Typically, there had been a sudden hemiparesis, described by the author explicitly as partial, incomplete, and transitory. Only 8 of 50 lost consciousness at the onset and then only briefly. Prodromal symptoms included fatigue, somnolence, headache, and vomiting.
Usually the face, arm, and leg were involved, but a limb or even part of a limb or the face alone could be affected. Dysarthria occurred by itself at times. There was no sensory loss or visual field defect. Dysarthria was commonplace and so severe at times that speech was incomprehensible, but aphasia did not occur. A striking finding was the tendency for recovery to occur, and after a few days the patient had only "a memory of his stroke." When the lesion lay directly in the internal capsule or pons, the paralysis might clear more slowly. The rapid recovery suggested that it was not a hemorrhage, but the author thought a small hemorrhage could behave like a lacune.

Even from the milder attacks, however, traces of a deficit remained, and sooner or later a similar involvement of the opposite side of the brain was the rule. The patient then entered a prolonged phase of the illness with a lacunar gait (marche à petits pas), impaired fine movements, increased tendon reflexes, Babinski signs, dysarthria, spasmodic laughing and crying, impaired memory, and even dementia and incontinence. Yet the picture did not resemble an ordinary double hemiplegia, and spastic contracture of the affected limbs never occurred.

Clinically, arteriosclerosis seemed to be the main factor, and in some cases there was an elevated arterial tension. It was exceptional for sugar to occur in the urine. Of 88 patients, $15(17 \%)$ died from hemorrhage into the basal ganglia; thus, lacunes were to be regarded as an important etiologic factor in intracerebral hemorrhage.

The author was convinced that no matter where the lesions were situated, whether in internal capsule, lenticular nucleus, or thalamus, the clinical picture was always the same, that is, a lenticular lesion caused a hemiplegia. Pontine lacunes did not have a special symptomatology unless it was incontinence. He made the exaggerated but nonetheless astute claim that, in a person over 60 who had a monoplegia or an incomplete hemiplegia without sensory loss or apoplexy, it was never a matter of a large hemorrhage or a cortical softening and not a matter of thrombosis or embolism but the result of a lacunar lesion situated in the basal ganglia. Lacunes accounted for $90 \%$ of hemiplegias in persons over 
age 60. Comte ${ }^{8}$ emphasized impaired balance.

Regarding terminology, Ferrand spoke of lacunar hemiplegia-a term that has much to recommend it-reserving the designation "hemiplegia vulgaire" for a more severe stroke with sensory loss. In another place, however, he said the absence of contracture would separate lacunar hemiplegia from "banal" hemiplegia, a term later used by Foix ${ }^{12}$ to refer to an ordinary, presumably pure motor hemiplegia.

Foix and Hillemand ${ }^{13}$ recognized 3 syndromes in pontine infarction-paramedian, short circumferential, and tegmental. The paramedian syndrome included [1] a large paramedian softening producing a simple hemiplegia that was worse in the upper extremity, and mild dysarthria, with no aspect of a monoplegia, [2] ramollissement-en-chapelet (string of beads): a chain of 2 or 3 small lacunes in the basis pontis characterized by a mild hemiplegia and difficult to diagnose, and [3] bilateral lacunes. The latter were very common and gave rise to bilateral pyramidal signs, pseudobulbar palsy, dysphagia, dysphonia, and spasms of laughing and crying. Foix and Levy, ${ }^{12}$ in laying down rules for distinguishing deep middle cerebral lesions from those located superficially, appreciated that partial lesions of the internal capsule were the equivalent of Marie's état lacunaire. The clinical picture was hemiplegia without hemianopia and with relatively little sensory loss. The speech disorder varied from dysarthria to anarthria to Broca's aphasia. Lhermitte and Trelles ${ }^{14}$ recognized the following pontine syndromes resulting from basilar arteriosclerosis: pontine hemiplegia, pontine paraplegia, and pontocerebellar pseudobulbar paralysis. In the last of these the pathological examination disclosed small lacunes disseminated through the pons.

Fisher, ${ }^{15}$ in a survey of strokes, referred to the role of hypertension and atherosclerosis in the pathogenesis of état lacunaire. Hughes and associates ${ }^{16}$ described 51 persons with chronic arterial hypertension with personality changes and pseudobulbar palsy. In 15 studied at autopsy, there were multiple lacunes in the basal ganglia, especially the head of the caudate nucleus and the putamen. Recognizing that these lesions lay in the territory of the penetrating arteries, the authors suggested, as the cause of the infarcts, eddying in the stem of the middle cerebral artery interfering with flow into the penetrating branches. The authors did not refer to older descriptions of état lacunaire. Fisher in 1959 presented a summary of the data to be reported in the present paper. ${ }^{17}$

\section{THE PRESENT STUDY}

In a series of 1,042 consecutive adults whose brains were removed and examined at autopsy, a thorough macroscopic search for lacunes was made. The location, size, and appearance of the lacunes were noted along with the occurrence of hemorrhage or infarcts other than lacunes. The cerebral and cerebellar cortex was especially examined for signs of involvement. As a rule, horizontal sections of the brain were made, since this enabled a thorough examination of the cerebral arteries, but in our opinion the anatomy of lacunes is better appreciated in coronal sections of a hemisphere. In all cases the brain was examined personally. The degree and distribution of cerebral atherosclerosis and the state of the carotid systems in the neck were investigated. On the clinical side, data concerning hypertension, diabetes, atrial fibrillation, blood Wassermann reaction, and other special conditions were tabulated. Information about smoking was not obtained. Finally, the correlation of the patient's mental and neurological condition with the occurrence of lacunes was undertaken.

\section{RESULTS}

Of the 1,042 persons, 114 (11\%) had one or more lacunes, a figure in close agreement with the finding of $10 \%$ in a previous study of 432 consecutive cases. ${ }^{18}$ In some 24 patients, concomitant large intracerebral hemorrhages may have obliterated adjacent lacunes. Of the total series, 71 were male and 43 female. The ages at death (when available) were 20 to 29 years, 1 person; 30 to 39,$1 ; 40$ to 49,$8 ; 50$ to 59,$21 ; 60$ to 69,$38 ; 70$ to 79,29 ; and 80 to 89,13 . In all, the lacunes totaled 376 , an average of about 3 in each brain. The lenticular nuclei were the favorite site, with 138 of the 376 (37\%) almost always in the putamen (right 62 and left 76). Following in order were pons, 59 (16\%) (right 22 and left 37); thalami, 52 (14\%) (right 18 and left 34); caudate nucleus, $38(10 \%)$ (right and 
left 19); the posterior limb of the internal capsule and the corona radiata immediately above, $38(10 \%)$; the frontal lobe white matter anterolateral to the head of the caudate nucleus, $16(4 \%)$; the white matter lateral to the atrium of the lateral ventricle, $9(2 \%)$; the anterior limb of the internal capsule, 8; corpus callosum, 7; cerebellum, 6 ; the white matter of the parietal lobe, 2; the upper central white matter, 1; the occipital lobe white matter, 1; and the temporal lobe white matter, 1.

There was 1 lacune in 29 patients, 2 lacunes in 25,3 in 17,4 in 12,5 in 4,6 to 10 in 18 , and more than 10 in 9 . In the last group, 2 persons had 15 and 2 had 14 lacunes.

Thirty-two persons had 1 lacune or more at 1 site, 14 persons at 2 sites, 22 at 3,6 at 4 , 5 at 5 , and 6 at 6 and 2 at 8 different locations. One of the last 2 had lesions in putamen, caudate, lateral to the atrium, corona radiata, thalamus, pons, frontal white matter, and cerebellum.

As might be anticipated from the overall frequency of lacunes at each site, the most frequently involved region in the 32 patients with a lesion or lesions at 1 site was the lenticular nucleus ( 14 persons). Then followed pons, internal capsule and corona radiata, thalamus, and caudate. In the 41 persons with lesions at 2 sites, the most frequent combinations were lenticular nucleus and pons (9), lenticular nucleus and caudate, lenticular nucleus and thalamus, and lenticular nucleus and internal capsule. In the rest, almost 50 different combinations were represented. A special analysis did not show a significant trend for multiple lesions to be predominantly unilateral. Of all the lesions, there was a slight preponderance on the left side of the brain in the ratio $1.4: 1$.

The lenticular nucleus was involved in 75 persons. (65\% of the total), pons in 45 (39\%), thalamus in $37(32 \%)$, posterior internal capsule and corona radiata in 31 (27\%), caudate nucleus in 24 (21\%), frontal white matter in 13, white matter lateral to the atrium of the ventricle in 8 , anterior limb of internal capsule in 7 , cerebellum in 7 , and corpus callosum in 6.

Most lesions were typical lacunes-small trabeculated cavities representing old healed infarcts. Only about 15 were of recent origin, showing early or advanced liquefaction necrosis. Lacunes in the gray matter were often linear, irregularly stellate, and more collapsed than those in white matter that tended to maintain the form of a rounded cavity. It was often difficult to tell if 2 or more lacunes in the same region were really separate or part of 1 irregular lacune. Even when the lacunes were separate, there was no way in the present study of determining whether a single vascular lesion was responsible for the 2 or more lacunes. In only a few instances could a vessel be identified within the lacunes and whether artery or vein was uncertain.

The lacunes were usually pale, but in 30 persons they were described as brown or amber. In 25 of these the lacunes were in gray matter (putamen, thalamus, or caudate) and in 5 the white matter ( 4 in the pons and 1 in the internal capsule). The term honey-colored was used to describe the appearance of multiple small lacunes in the putamen. The lesions were never frankly hemorrhagic and in only 1 person was the lacunes orange-colored and then only partly.

The exact position of the lacunes in the involved region was not always documented, but the following information could be gathered from descriptions and diagrams. Fortyfour putaminal lacunes were situated as follows: posterior, 13; middle, 13; anterior, 6; and lateral, 2 and 1 each as, most posterior, lower part, midanterior, anterolateral edge, upper, superolateral, anterior putaminocapsulocaudate, posterior putaminocapsular, putaminocaudate, and disseminated. The term $\mathrm{pu}-$ taminocapsulocaudate or fraction thereof refers to single lesions that extended to involve the 2 or 3 named regions. Anterior means those involving the anterior limb of the internal capsule and the head of the caudate nucleus. Posterior means those involving the posterior limb of the internal capsule and the body of the caudate nucleus. A difficult problem was determining whether a putaminal scar extended significantly into the internal capsule, thus possibly furnishing the basis in life for paralysis of limbs.

In the pons, 30 of 40 lacunes were described as in the midbasis on one or both sides, 4 in the basis but near the medial lemniscus, 3 near the midline, and 3 in the upper basis pontis. 
Twenty-four thalamic lacunes were described as middle or central, 12; upper anterior, 2; and lateral, 2 and one each in midlateral, midanterior, medial, upper, pulvinar, posterior lower, lower, and upper lateral. Only $1 \mathrm{ex}-$ tended to the posterior limb of the internal capsule and 1 to the cerebral peduncle (pedunculothalamic). All except 2 caudate lacunes were in the head of the caudate nucleus. There were 3 anterior capsulocaudate lesions, 2 posterior capsulocaudate lesions, 1 anterior putaminocapsulocaudate, 1 posterior putaminocapsulocaudate, and 1 putaminocaudate.

Lacunes of the posterior limb of the internal capsule usually were in the upper quarter of the capsule adjacent to the corona radiata. In the anterior limb and genu of the internal capsule the lesions were at a lower level. Corona radiata lesions were in the uppermost capsule superior to the body of the lenticular nucleus and even above the plane of the body of the caudate nucleus. A not uncommon site for lacunes was the central white matter of the frontal lobe anterolateral to the head of the caudate nucleus in the territory of the medial penetrating branches of the middle and anterior cerebral arteries. The white matter lateral to the atrium of the lateral ventricle was also a favorite site. The arterial supply to this territory was not determined with certainty, but injection studies indicated that it probably is a branch of the superficial middle cerebral artery. Of the corpus callosum lesions, 5 were in the genu and 2 in the splenium or forceps major. Four of the cerebellar lesions were close to the dentate nucleus and 2 nearby in the middle cerebellar peduncle. Only 1 lacune was identified as wholly in the globus pallidus. Only 4 or 5 lesions were identified as definitely in the cerebral white matter supplied by branches of the superficial cortical arteries. A small border-zone infarct in the white matter approximately $2 \mathrm{~cm}$. lateral to the corpus callosum may closely resemble a lacune but has a much different pathogenesis, namely, a critical drop in the blood pressure in the carotid system. The presence of other border-zone infarcts may enable a correct interpretation. No lesions analogous to lacunes were found in the cerebral or cerebellar cortex despite a painstaking search.

The size of the lacunar scars was usually
1 to $4 \mathrm{~mm}$., ranging up to $17 \mathrm{~mm}$. (see table). Because of irregularities in the shape of the lacunes the measurements were not wholly accurate but gave an idea of the size of the lesions. In the putamen, pons, caudate, and thalamus, approximately $60 \%$ of the lacunes were 2,3 , or $4 \mathrm{~mm}$. in diameter. About $17 \%$ of the lacunes measured $10 \mathrm{~mm}$. or more in diameter. The size that an infarct may attain and yet qualify for the term lacune has not been set down, and it may seem pointless to do so. Preferably, the nature and site of the lesion rather than its size should be the chief criterion. It is suggested, however, that, in order to emphasize the unusual size of the larger lacunes, those $10 \mathrm{~mm}$. or more in diameter be designated as giant.

In this series there were 36 giant lacunes14 in the putamen, 5 in the head of the caudate nucleus, 5 in the internal capsule, 4 in the corpus callosum, 3 in the thalamus, 2 in the central white matter of the frontal lobe, 2 in the pons, and 1 lateral to the atrium of the lateral ventricle. Included in these were 2 capsulocaudate infarcts, 2 anterior putaminocapsulocaudate, 1 posterior putaminocapsular caudate, and 1 pedunculothalamic.

Although a typical lacune was not found in the cerebral peduncles, 4 lesions in that area were described as follows: [1] a tiny 2-mm. recent softening in a peduncle, [2] a 1- to 2-mm. pale slit cavity in a cerebral peduncle, [3] a recent disintegrating softening $15 \mathrm{~mm}$. in diameter in the anterior angle of the thalamus extending inferiorly to involve the right cerebral peduncle in the exit region of the third nerve (embolism possibly responsible; see clinicopathologic correlation No. 4), and

NUMBER OF LACUNES OF DIFFERENT SIZES AT EACH SITE EXPRESSED AS A PERCENTAGE

\begin{tabular}{lccccc}
\hline \hline Site & No. & \multicolumn{4}{c}{$\begin{array}{c}\text { Largest dimension of lacume } \\
(\mathrm{mm.})\end{array}$} \\
\hline & & $1-2$ & $3-5$ & $6-10$ & $10+$ \\
Lenticular & 84 & 30 & 41 & 11 & 8 \\
Caudate & 21 & 14 & 48 & 19 & 19 \\
Capsule and corona & & & & \\
radiata & 15 & 13 & 34 & 27 & 7 \\
Thalamus & 27 & 11 & 56 & 22 & 4 \\
Pons & 34 & 38 & 50 & 12 & - \\
Other & 23 & 20 & 31 & $\frac{43}{18}$ & - \\
\multicolumn{1}{c}{ Total } & 204 & 25 & $\frac{51}{6}$ & 18 & 6 \\
\hline
\end{tabular}


[4] adjacent to a region of severe stenosis of the posterior cerebral artery, the left cerebral peduncle was brownish, and the lateral thalamus and hippocampus were probably also affected. In Nos. 3 and 4 it is likely that a pedunclothalamic lesion had resulted from events in a posterior cerebral artery.

No lacunes were found in the pyramids of the medulla, and, indeed, none occurred in the medulla oblongata unless the scars of lateral medullary infarction are to be so classified. In this regard there is no good reason for excluding lateral medullary and pedunculothalamic infarction from the category of lacunes, although in the former vertebral artery occlusion is usually the cause rather than penetrating artery disease. At any rate, judging from the present data, lacunes limited to a cerebral peduncle or medullary pyramid are extremely rare.

Another type of lesion which was encountered twice was a clear, minimally trabeculated cavity $10 \mathrm{~mm}$. or more in diameter situated in the lower putamen and containing a penetrating vessel. Microscopic sections showed these lesions to be infarcts rather than giant état criblé formations.

Microscopically, a typical lacune showed an irregular cavity containing a few strands of fine fibrillar connective tissue, some of these enclosing a tiny artery or vein. Fatty macrophages were in the cavity, their number diminishing with the age of the lesion; macrophages filled with hemosiderin accounted for less than $1 \%$ of these cells. The walls of the infarct were comprised of a dense fibroglial matting in which were many plump astrocytes. The neighboring veins were often surrounded by 25 to 50 macrophages.

A search for the responsible vascular occlusion was undertaken in 7 persons, and occlusions were found in 6 in the smaller vessels of the region, that is, the penetrating arteries (or their branches) arising from middle cerebral, anterior choroidal, anterior cerebral, posterior cerebral, or basilar arteries. To enable a methodical investigation of the vascular anatomy of lacunes, serial histological sections have been prepared and the results of this study will be reported separately. In many instances the mouths of the penetrating branches from the middle cerebral, posterior cerebral, or basilar arteries were especially examined but were not occluded by atheroma in the larger vessel.

Associated lesions. Cerebral hemorrhage was associated with lacunes in 41 persons (35\%). There were large, fatal hemorrhages (more than $2 \mathrm{~cm}$. in diameter) in 17 , smaller hemorrhages in 17, and a combination of large and small in 7 . Of the larger hemorrhages, 17 were located in the putamen, 4 in the thalamus, 3 in the cerebellum, and 1 in the pons. There were 11 instances of slit hemorrhage, that is, a hemorrhage along the junction of the cortical gray and white matter. Multiple hemorrhages were not uncommon-2 hemorrhages in 3 persons, 3 in 2, 4 in 1, 5 in 2, and 10 in 1. This high incidence of hemorrhagic lesions in assosociation with lacunes is the basis for the often repeated advice that great caution must be used in prescribing anticoagulants for a patient suspected of having lacunar disease. ${ }^{15}$

Superficial infarction of the cerebral or cerebellar cortex was found in 30 cases (26\%). In 25 cases the infarcts were of major size and in 5 , minor. The infarcts were multiple in 18 and single in 12. The causes of these lesions were embolism in 13 , thrombosis in 7 , a combination in 1 , unknown in 8 , and "extreme platelet stuffing" in 1 . Of interest was the finding that 20 of the 30 patients had one or more lesions in the vertebrobasilar-posterior cerebral territory. Thrombosis involved the following vessels: internal carotid artery, 2; posterior cerebral, 3; anterior cerebral, 1; middle cerebral, 1; and middle cerebral superficial branch, 1 .

In 114 persons, atherosclerosis of the cerebral arteries had been graded as severe, moderate, mild, or absent. It was severe in $64 \%$, moderate in $20 \%$, mild in $15 \%$, and absent in 1\% ( 1 person). Comparable routine autopsies in the same age group but without lacunes showed atherosclerosis as follows: severe in $9 \%$, moderate in $13 \%$, mild in $32 \%$, and absent in $46 \%$. The close parallel of atherosclerosis and lacunar disease is thus strikingly apparent. The only patient without artherosclerosis was a man, age 46 , with malignant hypertension $(220 / 150 \mathrm{~mm} . \mathrm{Hg})$ who died of a combination of acute hypertensive encephalopathy, renal impairment, and cardiac failure. The blood cholesterol was reported to be $125 \mathrm{mg}$. 
percent. Autopsy showed only 1 lacune and mild aortic and moderate coronary atherosclerosis. On the other hand, another patient had moderate cerebral atherosclerosis at the age of 25. In general, the degree of atherosclerosis paralleled the number of lacunes but there were many exceptions in which several lacunes occurred with mild atherosclerosis of the basal vessels or only a single lacune was associated with severe atherosclerosis. A significant finding was that in approximately $50 \%$ of patients with lacunes atherosclerotic plaques extended into the small surface vessels over the cerebral and cerebellar cortex. This change which closely parallels the presence of high blood pressure ${ }^{19}$ did not occur in the 100 control patients.

The carotid systems were dissected in the neck in 73 of the 114 patients. In 2 , the internal carotid artery was totally occluded. The severity of carotid atherosclerosis varied from mild to most severe, but no definite relation existed between the degree of carotid atherosclerosis and the number of lacunes. Lacune formation was at times advanced, with mild atherosclerosis; conversely, a single lesion could be associated with severe atherosclerosis. It zan be safely concluded that carotid disease $\mathrm{pl} \pm \mathrm{ys}$ no direct part in the pathogenesis of lacunes unless it be to prevent them by occluding the carotid artery in the neck and thus lowering the intracranial arterial pressure distally. Of some 20 cases of curotid occlusion not included in the present series, lacunes were found in a cerebral hemisphere in 4 persons but never on the side of the occluded artery.

The question of hypertension in life was thoroughly investigated by studying the hospital record and, when necessary, by consulting the patient's personal physician. In lieu of this information a heart weight greater than 400 gm. with no other cause for the cardiac hypertrophy was accepted as evidence of high blood pressure. Hypertension was documented in all but 3 instances-examination in 89, history and heart weight over $400 \mathrm{gm}$. in 13 , history alone in 4 , heart weight over $400 \mathrm{gm}$. in 5, unknown in 2 , and normotensive (heart weight $360 \mathrm{gm}$.) in 1. Therefore, it can be concluded that lacunar infarets are directly related to hypertension. The normotensive patient had been treated for proved neurosyphilis ten years before, and the small lesions, all old, may have been due to meningovascular syphilis. One of the 2 with unknown history was an 87-year-old diabetic woman admitted in shock. The heart weight was 325 gm., and cerebral atherosclerosis was severe. The lacunes were old, and the patient may well have been hypertensive at the time they occurred.

Diabetes mellitus was recorded in only 13 (11\%), an indication that small-vessel disease of the brain is usually divorced from diabetes, at least the frank variety. The number of lacunes in the diabetic was approximately the same as in the nondiabetic persons. Six of these had superficial infarcts as well. The severity of cerebral atherosclerosis was not different in the diabetic and nondiabetic persons.

As was expected, other evidence of hypertension and atherosclerosis abounded in these patients. The high incidence of cerebral hemorrhage and cortical infarction has already been mentioned. An additional 45 patients had myocardial infarction, congestive heart failure, atrial fibrillation, aortic aneurysm, or a major peripheral vascular occlusion.

The clinicopathologic correlation. As a foreword here, it must be pointed out that the patients were generally admitted to the wards and received the careful attention of a teaching medical service. Nevertheless, a special inquiry for every detail of old cerebrovascular disease was not made, and only 9 patients were seen by a neurological consultant. The results described below can, therefore, not be regarded as fully reliable and must be accepted with reserve.

It was surprising to find that in 88 of the 114 , neither a history of a stroke nor clear evidence of a neurological deficit was found on examination. In the others, there was a history of a stroke or neurological deficit, but it was usually impossible to make a clear correlation because of the multiplicity and complexity of the lesions found at autopsy-numerous lacunes, superficial infarcts, and hemorrhages.

In only the following patients was the clinicopathologic correlation, for an individual lacune, at all possible: [1] six months before death right-sided hemiparesis with good recovery but some residuum; $7-\mathrm{mm}$. lacune in posterior limb of internal capsule on the left side, [2] a dizzy spell possibly related to a 
cerebellar lacune, [3] "mouth crooked for five to ten minutes a few months ago"; 2 lacunes in basis pontis, [4] right-sided ptosis and questionable left-sided weakness for sixteen days before death; pedunculothalamic lesion near third nerve, [5] slurred speech and weakness of the right arm seven years before, weakness of the left arm and leg one year before, and weakness and numbness of the right arm and leg and dysarthria for twelve hours eight days before final admission; one 10-mm. lacune in the posterior limb of the internal capsule and a 3-mm. lacune in the basis pontis, [6] weakness of right arm and leg three months before death, left hemiplegia, left facial weakness, and right Babinski sign one day before death; 12 lacunes, with 1 in the posterior limb of the internal capsule and 2 in the basis pontis, [7] six years before final admission 13 attacks of right-sided transient pure motor hemiplegia over a five-day period ending in a persistent stroke, good recovery; lacunes in left corona radiata and left pons, and [8] numbness of arm and leg for several hours six months before final admission; lacunes only in putamen and caudate.

Though it is expected that lacunes in the putamen, head of caudate, thalamus, frontal white matter, and corpus callosum might be silent, lesions of the posterior limb of the internal capsule, corona radiata, and basis pontis should elicit motor symptoms with some regularity. This was far from the case in this series, however, for at least 43 pontine lacunes were apparently silent. In regard to the posterior internal capsule and corona radiata, at least half the lesions had caused no symptoms that were reported. Even giant lacunes were apparently silent in 25 of 30 instances. If it is assumed that lacunes involving the motor tracts will cause some symptoms, albeit mild, then it follows that roughly $35 \%$ of all lacunes should have elicited a motor deficit, since of the 376 lesions 97 involved the corona radiata, internal capsule, or pons.

In regard to the clinicopathologic correlation for multiple lacunes (état laucanaire) the classical picture of pseudobulbar palsy might have been anticipated in many of the patients at the final admission, but this was the exception; even analysis of those with more than 10 lacunes showed that the patient, although far from well, usually still lived at home and was able to be up and around, and dementia, if present at all, was mild. In all cases the hospital files were thoroughly examined for any evidence of mental deterioration, and often inquiries were made of the patient's personal physician. It may be concluded that this group of patients did not often show the classical picture of pseudobulbar palsy (marche à petits pas, episodes of laughing and crying, dysarthria, incontinence, or imbalance), and dementia was not advanced. It is to be recalled that Marie's cases were from the wards of Bicêtre Hospital for chronic invalids so that he as well as Hughes and associates ${ }^{16}$ was probably examining a highly selected group of patients at one extremity of the spectrum of lacunar disease. Also, in the present series the patients were often elderly ( 80 over the age of 60 years), and any mental deterioration may have been attributable to senility. It should be added that the patients who were most disabled mentally and physically showed, in addition to the lacunes, either superficial infarcts or multiple hemorrhages, but such persons were excluded from the above analysis, since only the effect of multiple lacunes was being assessed. In none were the features of parkinsonism described, and support for the concept of arteriosclerotic parkinsonism was not forthcoming. ${ }^{19}$ There may have been an inordinate frequency of fractured femur in the group as a whole. In assessing the neurological symptomatology of état lacunaire, a control group of elderly patients without lacunes should be studied or only patients under the age of 50 or so should be included.

The pathogenesis of lacunes. In the preceding analysis it was demonstrated that hypertension and cerebral atherosclerosis are closely correlated with lacunes. As the penetrating arteries running to the lacunes were not systematically examined, however, the essential vascular change underlying lacunar formation remains at present undisclosed. As mentioned above, the cause of the small-branch occlusion appeared not to be obstruction of the mouths of the vessels by atherosclerosis of the parent artery. Occasionally, a cerebral embolus may lodge in the middle cerebral or posterior cerebral stem and block the mouths of the penetrating artery, producing deep infarction with 
relative sparing of the superficial distribution of the artery; it is conceivable that this might rarely be the mechanism of lacune formation.

The possibility of embolism to the penetrating arteries themselves has not been fully discussed as yet. In most instances, there seemed to be no question of embolism, but to gather more facts the site of infarction in 50 consecutive pathologically studied persons with cerebral embolism was analyzed. The evidence for embolism included the finding of an embolus in situ in the involved cerebral artery, a ready source of embolic material in the heart, or embolic infarcts in other organs (kidney or spleen). The carotid systems always were dissected in the neck. Fifty persons had 100 superficial and 18 deep infarcts. Five of the 18 deep lesions were large infarcts resulting from arrested embolic masses blocking the mouths of adjacent penetrating vessels. The other 13 were typical lacunes and occurred in patients with essential hypertension and atherosclerosis. To obviate this coincidence a group of 34 nonatherosclerotic, normotensive, younger persons with embolism were analyzed separately. In these, there were 62 superficial cortical lesions but no deep lacunar infarct. It can be concluded from this that embolism to penetrating branches is an uncommon event. Nevertheless, since embolism to branches of the central retinal artery is not uncommon, it is anticipated that emboli will occasionally find their way to the penetrating branches of the brain and cause a lacune.

Our preliminary studies indicate that an unusual thrombotic process will prove to be the cause of lacunes. From the close relationship of hypertension and lacunes it can be predicted that the prevention or relief of hypertension in the clinic will be an important measure in combating lacunar strokes.

\section{SUMMARY}

Of 1,042 persons examined at autopsy, 376 cerebral lacunes were found in 114 . The lacunes were studied in regard to incidence, number, location, and size. Most frequently involved in descending order were the lenticular nucleus, pons, thalamus, caudate, and internal capsule-corona radiata region.

A relationship of lacunes to hypertension and cerebral atherosclerosis has now been amply confirmed. Lacunes were not related to internal carotid artery disease, cerebral em. bolism, or diabetes.

In these cases in which the patient was admitted to the general medical wards there was usually no history of a stroke and, if there was, a good clinicopathologic correlation was impossible because of incomplete details, as well as the multiplicity and complexity of the lesions found at autopsy (infarction and hemorrhage). In this series, advanced pseudobulbar palsy and dementia were apparently not prominent, and the great emphasis on these signs in the literature has probably been the result of studying specially selected cases. The responsible arterial lesion can at present only be surmised, and there is a need for further studies of the vascular process.

\section{REFERENCES}

1. FISHER, C. M., GORE, I, OKABE, N., and WHITE, P. D.: Calcification of the carotid siphon. Circulation (in press ).

2. DURAND-FARDEL, M.: Traité du Ramollissement du Cerveau, Baillière. Paris: 1843.

3. Proust, A.: Des Différentes Formes de Ramollissement du Cerveau. Thèse d'aggrégation-médicine. Paris: 1866.

4. Laborne, J. v.: Le Ramollissement et la Congestion du Cerveau. Paris: 1866.

5. Bounnevilte: De l'hémianesthésie liée à une lésion d'un hémisphere du cerveau. Prog. méd. (Paris) 1: $244,1873$.

6. LANDouzy, z.: Case report. Hémiplégia droite-contracture tardive et atrophie musculaire des membres droits. Prog. méd. (Paris) 5:992, 1877.

7. RAYMoND, F.: Sur la pathogénie de certains accidents paralytiques observés chez des vieillards. Rev. mèd. $5: 705,1885$.

8. Compe, A.: Des paralysies pseudo-bulbairies. Paris Thesis, 1900 , No. 436.

9. Marue, p.: Des foyers lacunaires de désintégration et de différents autres états cavitaires du cerveau, Rev Méd. (Paris) 21:281, 1901.

10. Ferrand, J.: Essai sur l'hémiplégie des vieillards. Les lacunes de déstintégration cérébrale. Paris Thesis, 1902.

11. DUPRE, E., and DEvaux, A.: Foyers Iacunaires de désintégration cérébrale (note sur le processus histogénique). Rev. neurol. 9:653, 1901.

12. FoIx, C., and LEVY, M.: Les ramollissements sylviens. Syndromes des lésions en foyer du territoire de l'artère sylvienne et des ses branches. Rev. neurol. $2: 1,1927$

13. Forx, $C_{\text {., }}$ and Hullemand, P.: Contribution à l'étude des ramollissements protubérantiels. Rev. Méd. (Paris) $43: 287,1926$.

14. LHermirt't, J., and TreLles, J. o.: L'artério-sclérose du tronc basilaire et ses consequences anatomo-cliniques. Jb. Psychiat. Neurol. 41:91, 1933.

15. Fisher, c. M.: Concerning strokes. Canad. med. Ass. J. $69: 257,1953$.

16. HUGHES, W., DODGSON, M. C. H., and MAC LENNAN, D. c.: Chronic cerebral hypertensive disease. Lancet 2: 770,1954 .

17. Fishek, C. M.: In: Fields, W. S.: Pathogenesis and Treatment of Cerebrovascular Disease. Springfield: Charles C Thomas, 1961.

18. Fisher, M.: Occlusion of the carotid arteries, Arch. Neurol. Psychiat. (Chic.) 72:187, 1954.

19. FISHER, M.: Concerning cerebral arteriosclerosis. J Amer. Geriat. Soc. $2: 1,1954$. 


\section{Neurology}

\section{Lacunes: Small, deep cerebral infarcts}

C. Miller Fisher

Neurology 1965;15;774

DOI 10.1212/WNL.15.8.774

This information is current as of August 1, 1965

$\begin{array}{ll}\text { Updated Information \& } & \text { including high resolution figures, can be found at: } \\ \text { Services } & \text { http://n.neurology.org/content/15/8/774.citation.ful } \\ & 1 \\ \text { Citations } & \text { This article has been cited by } 52 \text { HighWire-hosted } \\ & \text { articles: } \\ & \text { http://n.neurology.org/content/15/8/774.citation.ful } \\ \text { l\#\#otherarticles } & \\ & \text { Information about reproducing this article in parts } \\ \text { (figures,tables) or in its entirety can be found } & \text { online at: } \\ & \text { http://www.neurology.org/about/about_the_journal } \\ & \text { \#permissions } \\ & \text { Information about ordering reprints can be found } \\ & \text { online: } \\ \text { http://n.neurology.org/subscribers/advertise }\end{array}$

Neurology ${ }^{\circledR}$ is the official journal of the American Academy of Neurology. Published continuously since 1951, it is now a weekly with 48 issues per year. Copyright (C) 1965 by the American Academy of Neurology. All rights reserved. Print ISSN: 0028-3878. Online ISSN: 1526-632X.

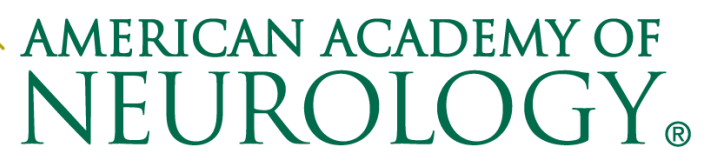

